\title{
Ground support installation quality controls and possible pitfalls: a case study from a critical fall of ground contract rehabilitation project
}

\author{
BN Viljoen SRK Consulting (Canada) Inc., Canada \\ BA Murphy SRK Consulting (Canada) Inc., Canada
}

\begin{abstract}
Ground support installation in underground mines is a routine task that is performed daily to maintain a stable excavation and safe working environment. The ground support design is usually specified in terms of the support type, capacity, dimensions and pattern of ground support while the support capacity is based on manufacturer's specifications and some trials. In other cases, support standards from similar operations are adopted and assumed to fulfil the intended purpose. Once the support design is implemented, it is not unusual that the process becomes 'business as usual' and less attention is paid to the controls required to achieve the designed support capacity. This is likely more prevalent in shorter-term contract applications that have changing teams and variable equipment usage.
\end{abstract}

A recent project demonstrates how ongoing extensive testing and routine quality control was instrumental in identifying problems with the support product selection, equipment setup, and installation procedure. Support product selection based on supplier's specification with limited consideration of other factors proved to be, in some cases, a fatal flaw. Support installation/application and implementation procedures adopted from similar operations provide a reference point, but site-specific implementation must consider potential differences, such as variations in the installation equipment, rock mass conditions, and support products. These factors must be assessed and resulting processes must be verified before implementation of a support design. This paper presents a case study to illustrate potential pitfalls when adopting the 'standard approach' and the value of support trials, routine testing, and the need for continuous quality assurance, especially for shorter-duration contract projects.

Keywords: ground support, testing, implementation, quality control, quality assurance

\section{Introduction}

Support design for underground excavations has been studied extensively, and various industry accepted approaches have been developed. These approaches may include the use of empirical design charts, kinematics, and numerical modelling. Great effort is made to collect geotechnical data, analyse excavation stability, and define support requirements. In the authors' experience, developing operational support standards and specifying support products/equipment doesn't always receive the same level of attention. In several instances, it was found that the product selection and installation procedures were based on experience from other operations within the same company, product brochures, and manufacturer's specifications. Benchmarking the support product selection and installation procedures against other operations is a good practice, but these assumptions must be adequately tested before implementation. Seasoned operators are often simply trusted to operate based on previous experience, but they need to be trained in the specific installation procedures and requirements. The support systems are expected to perform as designed, but this assumption must be verified. A number of operating mines were found to rely on established support system/processes with limited ongoing quality control of the installation/application process and the actual support performance is often not verified. Without the necessary quality control, testing, and performance validation, the support system cannot be assumed to perform as designed. This 
case study presents some of the pitfalls and quality issues encountered while establishing ground support standards and installation procedures for a critical fall of ground rehabilitation contract project and during the ongoing quality control.

\section{Background}

A recent project involved the extensive rehabilitation and support of a large fall of ground in a previously unsupported underground mine. As the project engineers, the authors were responsible for rock mass characterisation, stability assessment, establishment of support requirements and approaches, engineering oversight, and quality assurance. The property owner elected not to perform the rehabilitation work and the ground support (fibre-reinforced shotcrete, wire mesh, straps, resin rebar and cables) was installed by an established mining contractor. The construction documents specified support type and performance specifications, but the contractor was responsible for the support product selection and installation. The contractor selected support products and equipment primarily based on the supplier's specifications and previous project experience. The first pass installation procedures were based on the equipment selected and the contractor's experience at other projects. A detailed testing program was required to verify the support performance and installation processes. The engineering group was to review the specification of the selected product, test results, and installation procedures to ensure that the minimum performance specifications were consistently met. Changes to the support product selection and installation procedures were required to be evaluated to meet the specified performance. The contractor was required to perform routine quality control, while the engineer would have provided quality assurance to ensure that the installed support met the design specifications.

\section{Case studies and actual observations}

This case study presents examples from a project where comprehensive testing programs were completed on each support component prior to implementation. The elevated risk associated with the project required absolute conformance with the assumed support performance, and additional effort was made to ensure that each support element met the minimum requirements. Testing of the support installation/application process highlighted the potential pitfalls in the design and implementation of support products. The knowledge gained was used to update the standard operating procedures and to develop a detailed quality control and quality assurance program.

\subsection{Resin rebar}

\subsubsection{Hole diameter}

Resin rebar design was based on $19.5 \mathrm{~mm}$ rebar installed in holes with a diameter less than $34 \mathrm{~mm}$, a contract specification, as guided by generic resin supplier's specifications. The contractor elected to install the resin rebar with mechanical bolters utilising $33 \mathrm{~mm}$ drill bits, expecting hole diameters not exceeding $34 \mathrm{~mm}$. Initial short encapsulated pull testing provided highly variable results with nearly $80 \%$ of the tests failing to achieve $10 \mathrm{t}$ on a $300 \mathrm{~mm}$ encapsulation test or the results were questionable due to the recorded displacement. Figure 1 presents the results from a single testing session.

Troubleshooting tested the sensitivity to spin speed, number of rotations, cure time, and fast resin containment with no noticeable improvement.

The drill steel on the mechanical bolter was not compatible with smaller diameter drill bits and assessing the sensitivity to hole diameter was not practical. Inspections of the holes with a borehole camera did indicate variable levels of breakout and inconsistent hole diameters. Two alternative approaches were used to assess the sensitivity to hole diameter and breakout:

- Mechanical bolter: $22 \mathrm{~mm}$ rebar installed in holes drilled with a $33 \mathrm{~mm}$ drill bit. Spin speed, and number of rotations remain unchanged (Figure 2). 
- Jackleg: $19.5 \mathrm{~mm}$ rebar installed in holes drilled with a $32 \mathrm{~mm}$ drill bit. Spin speed was adjusted to achieve 30-40 revolutions at the measured rotation speed (Figure 3).

The results of the alternative short encapsulation pull testing showed a remarkable improvement, with all the tests exceeding $10 \mathrm{t}$ with limited displacement. The short encapsulation pull test results are presented in Figures 1 through 3.

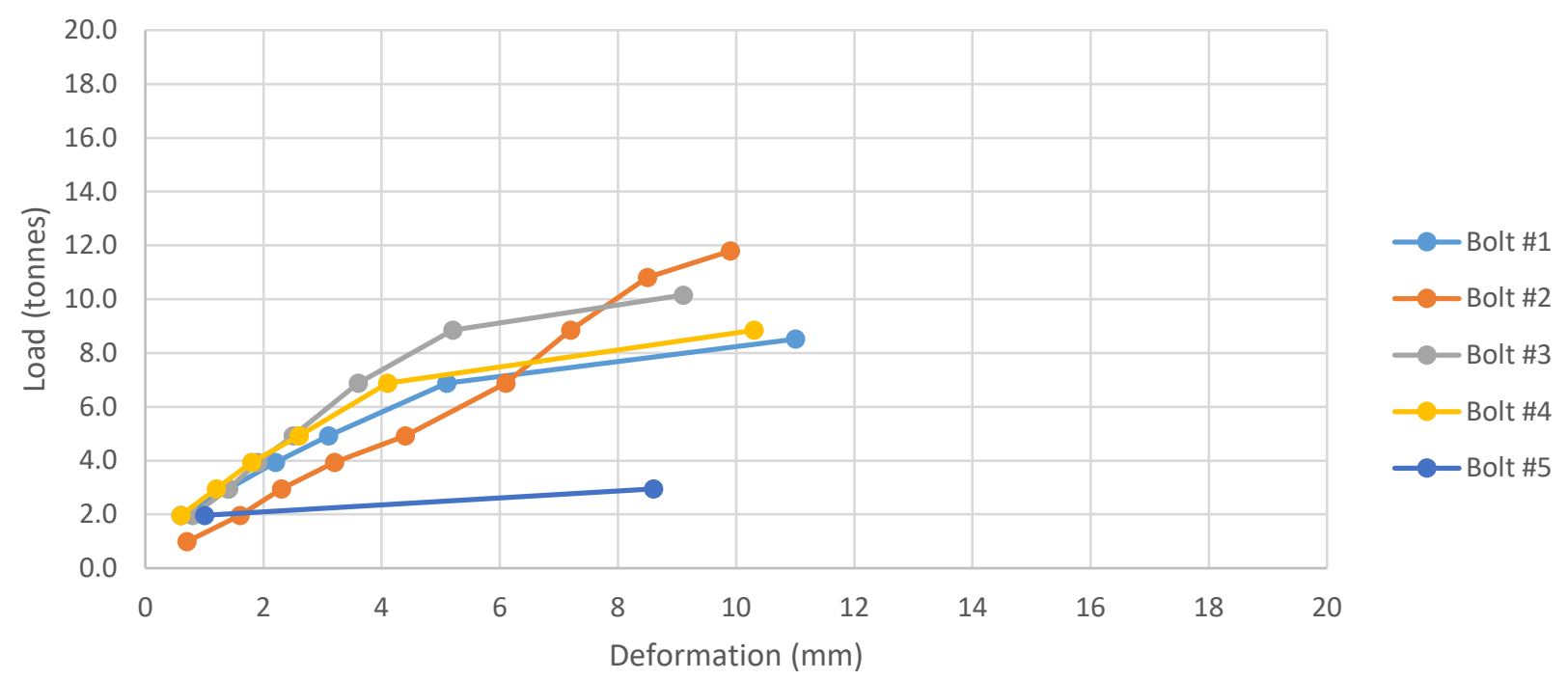

Figure 1 Short encapsulation pull test results. The $19.5 \mathrm{~mm}$ diameter rebar was installed in holes drilled with a mechanical bolter using $33 \mathrm{~mm}$ bits

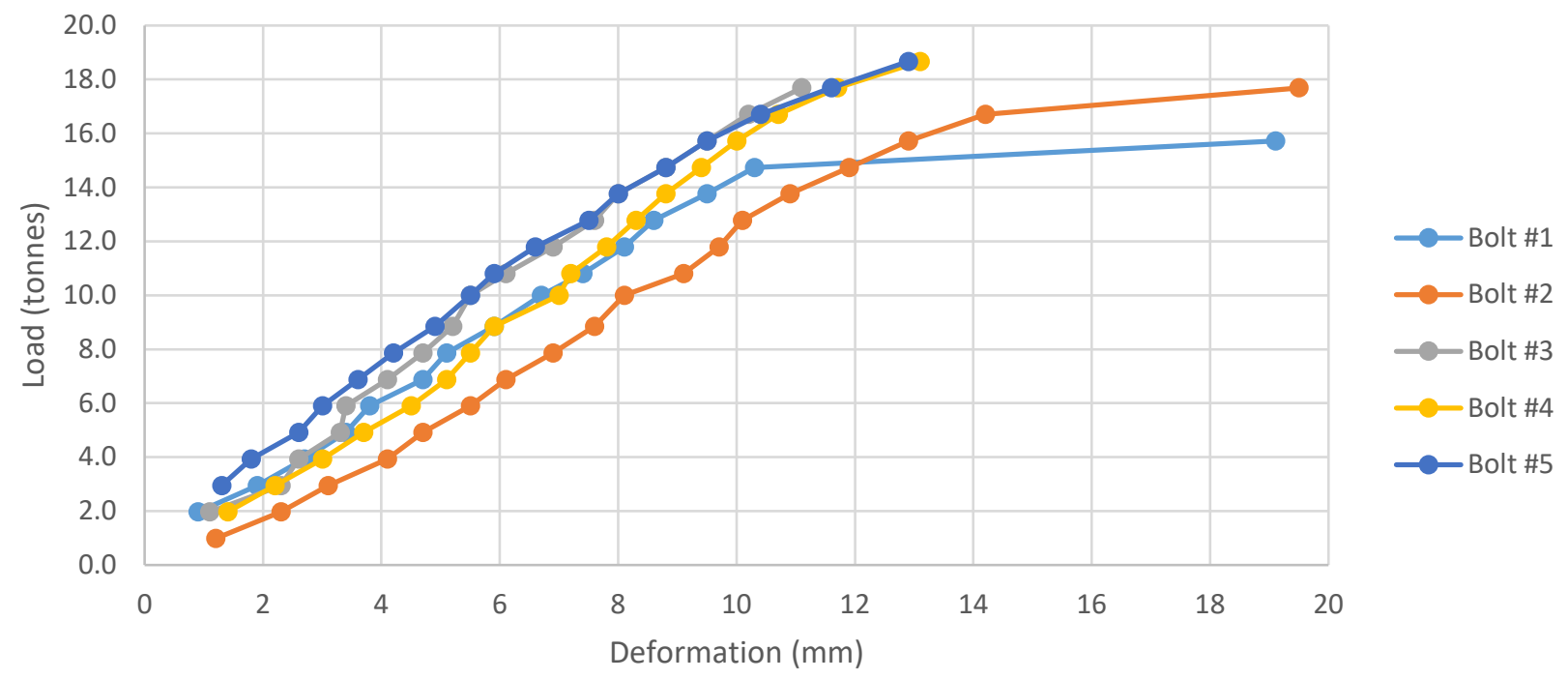

Figure 2 Short encapsulation pull test results. The $22 \mathrm{~mm}$ diameter rebar was installed in holes drilled with a mechanical bolter using $33 \mathrm{~mm}$ bits 


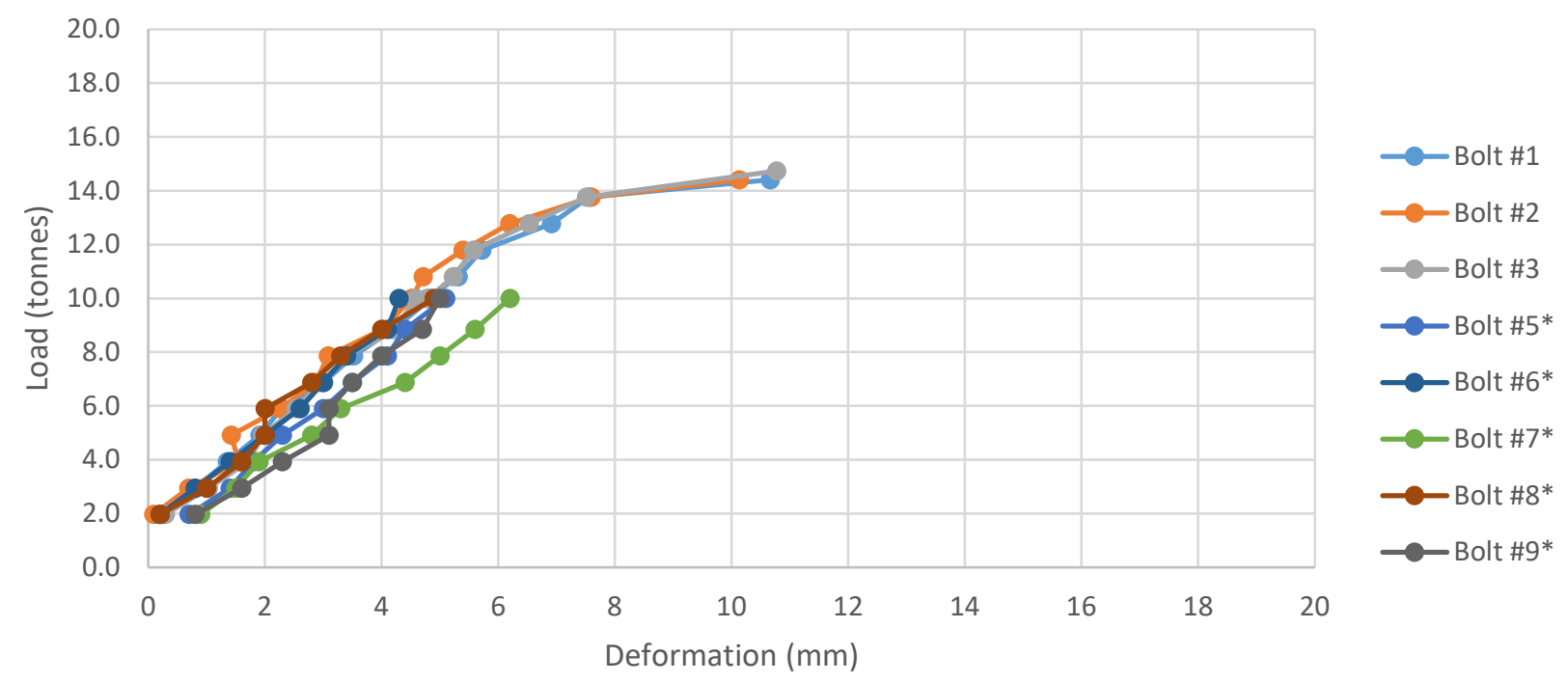

Figure 3 Short encapsulation pull test results. The $19.5 \mathrm{~mm}$ diameter rebar was installed in holes drilled with a jack legs using $32 \mathrm{~mm}$ bits. Tests indicated by an asterisk (*) were stopped when the load reached $10 \mathrm{t}$

Solutions:

- Installation with the mechanical bolters required $22 \mathrm{~mm}$ rebar installed in holes drilled with $33 \mathrm{~mm}$ drill bits.

- Installation of $19.5 \mathrm{~mm}$ rebar with jacklegs required a drill bit not exceeding $32 \mathrm{~mm}$.

\subsubsection{Spin speed/time}

Installation of the resin rebar required 30-40 revolutions of the rebar. Under- or over-spinning the resin will impact the resin strength and support performance. The result of under-spinning is poor mixing and low resin strength. Over-spinning will cause existing bonds to break, reducing the ultimate resin strength. The required number of rotations should also be achieved well within the resin set time. The number of rotations cannot be counted during installation, and installation procedures typically specify the spin time based on known rotation speed. Knowing the rotational speed during full column resin rebar installation is required. In this case, full column installations with the mechanical bolter required 7-9 seconds of spin, depending on the specific machine, to achieve the required number of revolutions.

Full column installations were performed with each mechanical bolter and the jacklegs to establish a baseline rotation speed. The installation rate and rebar rotation speed were determined for each installation using high speed video photography. The results indicated the following:

- The mechanical bolter's actual rotation speed didn't match the manufacturer's specification.

- Rotation speed for the two models of mechanical bolters wasn't the same.

- Rotation speed of the jacklegs was dependent on the air pressure and resin temperature.

Solutions:

- Determine the unique spin time for each type of equipment and adjust the installation procedure accordingly.

- Implement a minimum air pressure for resin rebar installation with jacklegs. 


\subsubsection{Install rate/spin time}

Resin rebar installation procedures typically assume that spinning is only initiated as the rebar is nearly fully inserted in the hole. This implies that the slow and fast resin is mixed for a similar time and number of rotations. Premature initiation of the rebar rotation makes it easier to insert the rebar when the equipment lacks the necessary thrust. This will, however, result in additional mixing of the slow resin as the spin time is based on the mixing of the fast resin.

The full column installations were evaluated to assess the rebar installation rate and mixing of the slow resin. The time it took to push the rebar through the slow resin and mix the fast resin was evaluated against the slow resin set time. The observations concluded that:

- The mechanical bolters had sufficient thrust to push the rebar to the end of the hole before initiating mixing. The mixing of the slow and fast resin was similar.

- Installation with jackleg was highly variable and depended on the air pressure and resin temperature:

- Insufficient air pressure reduces the thrust, requiring rebar rotation to insert the rebar. Premature rotation increases mixing of the slow resin.

- Cold $\left(<10^{\circ} \mathrm{C}\right)$ resin has a higher viscosity, which impacted the rotation speed and rebar penetration rate with the jacklegs. Rotation was required to insert the rebar and spin time exceeded the set time of the resin.

- Slower rotation speed in cold resin meant that the required mixing couldn't be achieved within the fast resin's set time.

Solutions:

- Implement a minimum air pressure for resin rebar installation with jacklegs.

- Ensure that resin is at a workable temperature $\left(\sim 20^{\circ} \mathrm{C}\right)$ prior to installation. This may require warming the resin.

- Select slow resin with appropriate set time.

\subsubsection{Equipment selection}

Mechanised support equipment selection for this project was primarily based on the need for remote installation ahead of the last line of ground support. Another consideration was the need to install 1.8-3.0 m resin rebar. The contractor selected the equipment from their existing fleet to meet the performance specification. The equipment manufacturer's specifications were reviewed, and some modifications were made to the equipment prior to mobilisation. The equipment could not be tested before mobilisation, and several pitfalls were encountered during commissioning and testing:

- The drill steel fitted to the mechanical bolters was not compatible with smaller drill bits. Replacing the drill steel would have been expensive and would have resulted in delays.

- The carousel couldn't easily change from one bolt length to the other.

- The resin injection system worked, but several resin cartridges ruptured during injections. The need to clean or redrill the holes resulted in lower productivity.

- A mobile compressor was used to install support with the jacklegs. The air pressure wasn't sufficient at all times for resin rebar installation. 


\subsection{Shotcrete}

Wet shotcrete had to be applied in advance of the last installed permanent support (resin rebar and cables) to secure the back and provide real support. Applying the shotcrete in an unsupported area required the use of an electro-hydraulic concrete sprayer with sufficient reach. The selected unit was capable of spraying premixed wet shotcrete in advance of the permanent ground support limit and simultaneously applying the necessary chemicals. During the commissioning and operation of the shotcrete system, several issues were encountered.

\subsubsection{Shotcrete mixing}

Mixed wet shotcrete had to be delivered to the shotcrete sprayer which required batching and mixing. Concrete mixing was tested with batching through the batch plant and directly in underground transmixers, as is sometimes done in underground mining operations. The mixing and concrete quality was assessed visually and through slump tests prior to application. Both the approaches provided variable results. Some of the problems encountered include:

- Inaccuracy when measuring the water resulted several batches not meeting the manufacturer's slump specifications.

- Filling the transmixer to the maximum capacity frequently resulted in poor mixing. Additional room was required to achieve adequate mixing.

- Inadequate cleaning of the transmixers affected subsequent batches. Several batches didn't meet the slump specification and had to be disposed.

- Delays in delivering and applying the concrete resulted in it setting in the transmixer. Concrete typically failed to meet the slump requirements and had to be dumped if not applied within 2 hours from adding the water.

Solutions:

- Precise measurement of the water was critical to achieve the specified slump and ultimate shotcrete strength.

- Mixing in the transmixer was successful, but required that the water and dry concrete mix not exceed about $\sim 2 / 3$ of the transmixer capacity.

- Thorough cleaning of the equipment was required after each shift.

- Concrete mixing and application had to be planned and scheduled. Concrete should not be mixed if it wouldn't be applied within $1-1.5$ hours.

\subsubsection{Shotcrete early and ultimate strength}

The shotcrete performance was evaluated based on the early and ultimate strength similar to the approach taken at Mount Isa (O'Toole \& Pope 2006). The early strength dictated the delay between shotcrete application and installation of the resin rebar and cables. The 28-day strength was tested against the support design. The early strength $(8,16,24$ hour) was evaluated using the Hilti penetration test (Hilti 2011) while the 7- and 28-day strengths were determined through laboratory testing of core samples (ASTM International 2018). During the project commissioning and at a few other times during the project, shotcrete strength did not meet the manufacturer's specification. Detailed quality control identified the following contributing factors:

- Variation from the ideal water to cement ratio.

- Time between mix and application. 
- Inaccurate accelerator application rate impacted the early and ultimate strength. Excessive accelerator addition resulted in high early strength and failure to meet the 7- and 28-day strength.

Solutions:

- Precise measurement of the water added to each batch.

- Proper planning to avoid delays between concrete mixing and application.

- Routine calibration of equipment to identify potential variations (e.g. rate of accelerator application).

- Detained quality control during the mixing and application (e.g. water to cement ratio, accelerator application, etc.).

- Quality assurance (early strength testing) for early detection of issues.

\subsection{Cable bolts}

\subsubsection{Early and ultimate grout strength}

Cable grout strength was monitored to assess the early and ultimate strength. The early strength was determined to assess the timing between grouting and tensioning as well as the early strength gain. The 7- and 28-day strength was determined to compare against the manufacturer's specifications and support design. The factors found to impact the grout strength included:

- Water to cement ratio.

- Temperature of the water and curing environment, which was believed to impact the strength curve.

- Poor cleaning of the grouting system, which affected several grout batches which failed to meet the design strength.

Solutions:

- Use an appropriate grout product intended for cable bolt installation.

- Determine the optimal water to cement ratio for the given environmental conditions through testing.

- Perform testing of the grout in the intended environment.

- Ensure consistency in grout mixing.

- Clean equipment properly after each use.

\subsubsection{Barrels and wedges}

The support design included $15.24 \mathrm{~mm}$ bulbed cables. The cables were grouted in the holes and post-tensioned with plates, barrels, and wedges. Barrels and wedges were ordered from the same supplier to be compatible with the specified cables. Issues encountered with the supplied barrel and wedge assemblies:

- Wrong size wedges. Some barrels were fitted with wedges designed for $17.78 \mathrm{~mm}$ cables.

- Mismatched wedges. Some assemblies contained one correct and one oversized wedge (Figure 4). Both these scenarios resulted in tensioned barrels slipping. 


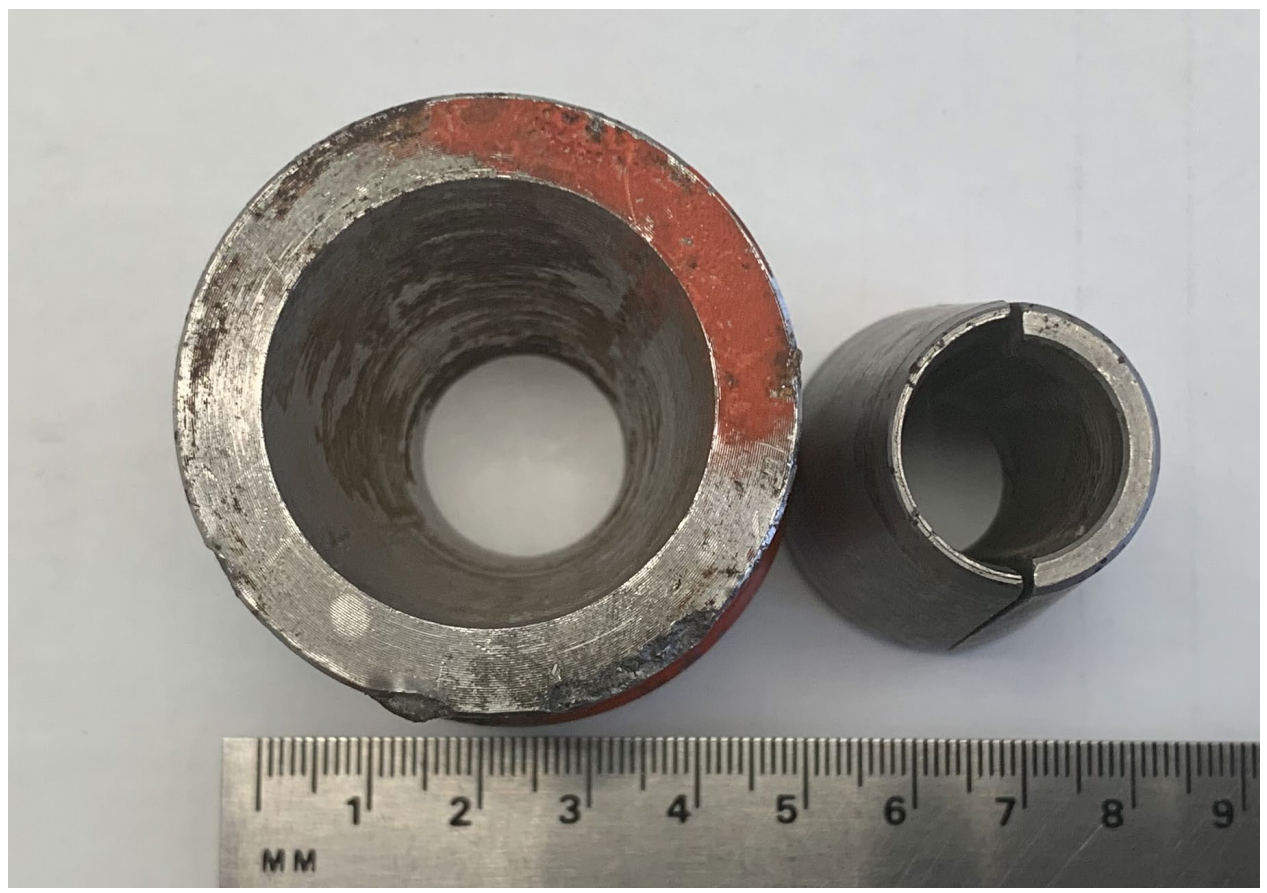

Figure 4 A barrel and wedge assembly containing one half of the wedge intended for $15.24 \mathrm{~mm}$ cables and one half of the wedge intended for $17.78 \mathrm{~mm}$ cables

Solutions:

- Verify that the correct barrels and wedges are purchased from the supplier.

- Physically check the barrels and wedges.

\subsubsection{Equipment}

This project required complete remote cable installation, including drilling of the holes, cable installation, and grouting. Suitable equipment was sourced and commissioned. The equipment met the technical requirements, but a few practical challenges were encountered:

- Grout mixer held sufficient grout to fill 5-6 holes, but the grout would set before the last cable was installed.

- The selected bulb size didn't fit the equipment despite matching the manufacturer's maximum specification. This resulted in using smaller bulbs than originally intended.

- Rollers feeding the cable tended to squeeze the bulbs closed, resulting in smaller bulbs.

Solutions:

- Develop a practical installation process of predrilling several holes, grout mixing and batch installation.

- Base support design on smaller diameter cables and bulbs or smooth cables.

\subsection{Dealing with contractors and setting up a contract}

Contractors are often employed to perform a range of tasks, including support installation. The mine/project owner is responsible for the establishment of the scope and technical requirements. The contractor then needs to provide the appropriate equipment, material, and personnel. This requires clear communication of the requirements and intended approach during the bid request and bid selection processes. During recent projects, the following issues were experienced: 
- Performance specifications were misinterpreted.

- The wrong equipment or equipment that is not compatible with the requirements was selected.

- Workers were not trained on the specific installation/application requirements.

- Procedures were poorly defined and implemented.

These complications resulted in costly delays to resolve the technical issues, train personnel, and establish procedures.

Solutions:

- Be very specific when defining the support specifications.

- Review the specification for each piece of equipment and ensure that it is totally compatible.

- Perform verification testing with the actual equipment and people.

- Review standard operating procedures (SOPs) and the support installation/application.

- Perform ongoing quality control and quality assurance - testing, planned task observations, spot checks, etc.

\section{Discussion}

Developing a ground support system is based on certain assumptions, which are largely dependent on the project phase, operation maturity, and knowledge of the project/operation. A well-established mine typically has a vast amount of information, experience with the conditions, and past performance knowledge. Support system approaches at these operations might be restricted by available equipment and the engrained current support practices. Specific shorter-duration contract projects rely on significantly less data or site-specific experience, but likely have more flexibility to select support products, installation equipment, and establish processes using best practice. In both cases, there are limitations associated with the design and implementation of the support (Dunn 2013). In the paper, Dunn discussed the risk associated with the support design and the implementation process. Most risks associated with support implementation (Table 1, next page) are classified as human error.

In the case of the project discussed in this paper, human error during the actual installation was not the primary contributing factor resulting in an underperforming system. The inability to review the actual support performance earlier resulted in a disconnect between the theoretical support specifications and actual performance, causing costly delays. In the authors' experience, a few typical assumptions are frequently made during the support design/specification, implementation, and routine evaluation:

- The support will generally meet the product specifications.

- Support standards and practices from other mines should be appropriate.

- The selected or available equipment will be suitable to install/apply the selected support products.

- The contractor crew would be familiar with the provided equipment and possible pitfalls.

To achieve the required overall support system performance, the implementation of support products/complete support systems are usually preceded by the development of a support standard and SOPs. Details like the bolt pattern and length, shotcrete thickness, coverage of the back and wall, need for additional cables, and so forth are captured in these support standards. A substantial amount of information is summarised in a minimal number of pages and details perceived to be unnecessary are excluded. 
Table 1 Uncertainty in ground support implementation (Dunn 2013)

\begin{tabular}{|c|c|c|}
\hline Description of uncertainty & Contributors and influencers & Type of uncertainty \\
\hline \multirow[t]{3}{*}{ Installation quality } & Inadequate installation procedures & Human error \\
\hline & Inadequate quality control systems & Human error \\
\hline & Poor training and competence & Human error \\
\hline \multirow{4}{*}{$\begin{array}{l}\text { Adherence to pattern and } \\
\text { spacing }\end{array}$} & Risk-taking behaviour & Human error \\
\hline & Production pressure & Human error \\
\hline & Poor training and competence & Human error \\
\hline & Convenience & Human error \\
\hline \multirow{2}{*}{$\begin{array}{l}\text { Application of the incorrect } \\
\text { ground support standard }\end{array}$} & Poor communication of the requirements & Human error \\
\hline & Design changes in the field & Design changes \\
\hline \multirow{2}{*}{$\begin{array}{l}\text { Not identifying a change in } \\
\text { ground conditions }\end{array}$} & Poor training and competence & Human error \\
\hline & Lack of understanding and awareness & Human error \\
\hline \multirow[t]{3}{*}{ Ground support performance } & Inadequate monitoring & Human error \\
\hline & Inappropriate monitoring & $\begin{array}{l}\text { Risk of using the wrong } \\
\text { geotechnical criteria }\end{array}$ \\
\hline & $\begin{array}{l}\text { Performance results not fed back into } \\
\text { design }\end{array}$ & Human error \\
\hline
\end{tabular}

SOPs are typically established for each type of support, but not always. The SOP provides more specific details around the actual support installation process and can be used for training and ongoing quality control. It was noted during this project and from other shorter-duration contract projects that the initial installation/application specifications are frequently based on product and equipment specifications. These assumptions should be validated during the initial testing and early implementation phases. Undertaking a comprehensive testing phase is essential to confirm the true performance of both the support products, equipment, and personnel under the existing site conditions. This verification process is sometimes omitted, and installation procedures are based solely on the theoretical equipment/product specifications and previous experience. In the most adverse cases, no installation procedures or oversight is provided, and workers rely on their personal, sometimes impertinent, experience.

During this project, a number of factors contributed to technical difficulties and the initial failure to meet the design specification. The most notable include:

- A detailed support design was developed specifying the support patterns, dimensions, and required performance, but it did not specify products. This was required to allow potential contractors to engage their supplier of choice and provide competitive bids. The choice to exclude specifics disconnected the support design from the support product and equipment selection. The installed support did not consistently meet the performance requirement as prescribed for the project.

- The equipment selection process did not necessarily consider the variation in environmental conditions and the associated challenges, e.g. sensitivity of resin rebar installation to resin temperature, penetration rate, and rotation speed/time. Equipment and installation procedures had to be tested in the specific environment. This required modification of the SOP and training of the personnel.

- SOPs used at other projects were presented as the base case. Additional testing was required to assess the support performance based on these installation procedures and adjustments were 
made where necessary e.g. variance in spin time when installing resin rebar with the mechanical bolters and jacklegs.

- The equipment was selected and prepared based on the support product specification with limited flexibility to make adjustments later, e.g. mechanical bolters were fitted with drill steel suitable for the expected conditions, with no opportunity to use smaller drill bits if rock conditions required it. The inability to use a smaller drill bit on the mechanical bolters necessitated the use of larger diameter rebar. This was costly and resulted in a delay.

- A lack of diligence and quality control throughout the material procurement and installation process resulted in incorrect support products being used e.g. receiving and installing the incorrect barrels and wedge assemblies.

The project presented in this case study encountered a number of technical challenges during the commissioning phase. These were due to assumptions made during the planning and implementation phases. Extensive testing of all support types highlighted these issues and corrective measures were taken to ensure that the required support performance was achieved. The installation procedures were updated, and personnel were trained on the specific installation requirements. The ongoing quality control and quality assurance identified any additional concerns and provided confidence that the required performance was achieved. Failure to identify and rectify these issues would have resulted in at least partial substandard support installation. The thorough testing/implementation program and ongoing monitoring proved invaluable to this project.

\subsection{Program start-up}

The start of a project or implementation of new support products can be challenging. Selection of support products, evaluation of equipment, testing, and implementation can be a daunting process. The flow diagram in Figure 5 is intended to provide guidance from the support selection to the ongoing support installation monitoring. The same approach can be used to assess established support installation practices.

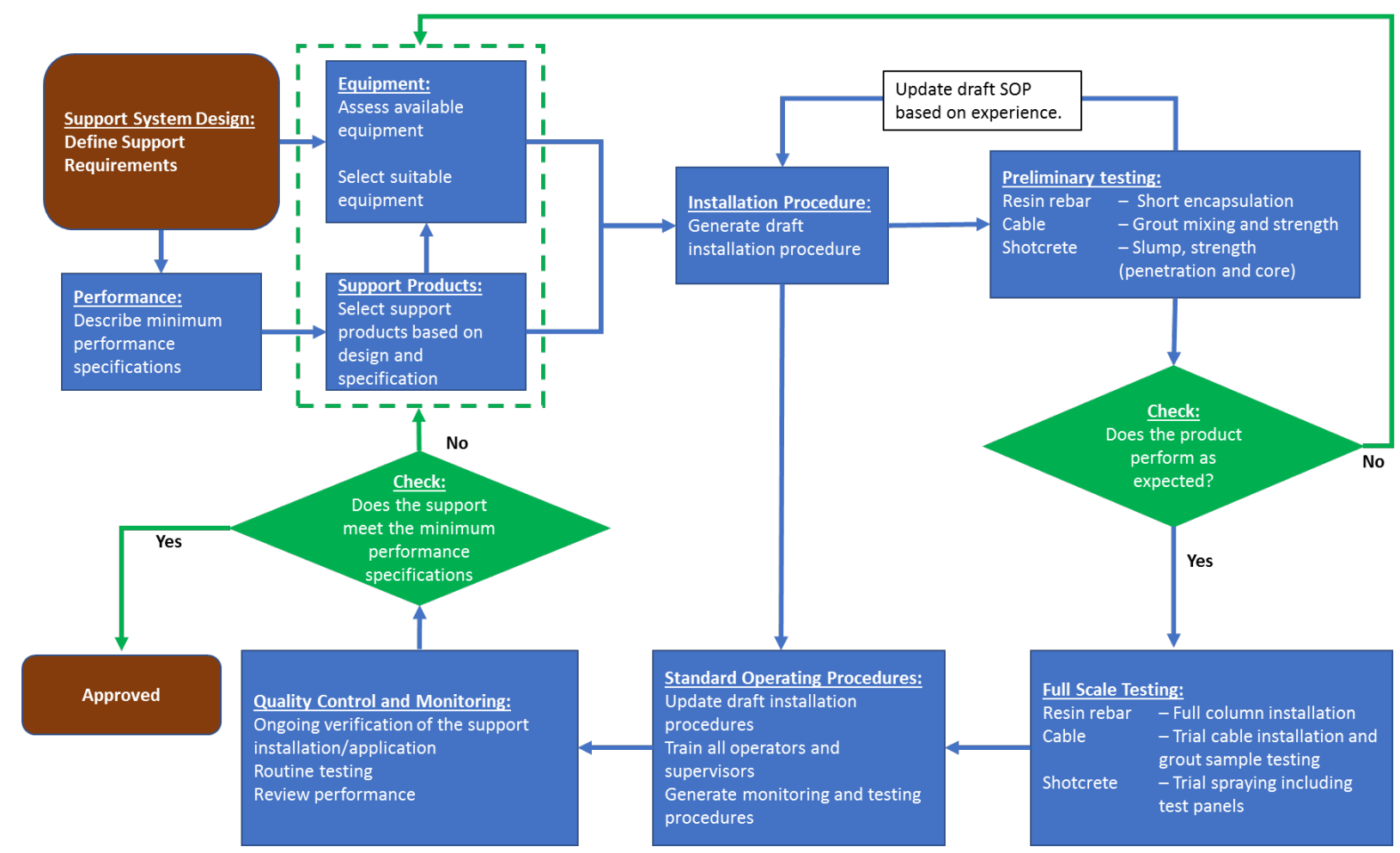

Figure 5 Flow diagram describing the ground support selection, testing, and implementation process 


\section{Conclusion}

Ground support design for underground excavations is a well-studied field and extensive effort is usually made to collect geotechnical data and assess the ground support requirements. The support requirements are described in detail in support standards and SOPs, and it is assumed that these specifications will be met with the selected support products, equipment, and installation/application procedures. This is particularly relevant to shorter-duration contract projects with limited site-specific experience and limited time for testing and commissioning.

Planning and implementation of the support product/systems is equally important in achieving the required support performance. The actual support and equipment selection, implementation and personnel training should receive the same level of consideration as the geotechnical evaluation and support design. A lack of attention during the planning and support implementation phase can lead to ineffective or underperforming support, as was the case at the start of this rehabilitation project.

A thorough evaluation, testing, and implementation process will increase the likelihood of achieving effective support installation/applications. The evaluation should consider the ground support material and equipment performance under the prevailing or expected site-specific conditions. The assumed performance needs to be verified through appropriate testing of both the selected support products and equipment. Implementation is the final step to achieve the expected support performance. Training, quality control, and continuous validation are required to maintain good quality support installation/application.

\section{Acknowledgement}

The authors acknowledge the personnel involved in the project with special thanks to Choong Eun Lee, Olga Gibbons, and Brad Klassen of SRK Consulting (Canada) Inc. for their invaluable support throughout the project.

\section{References}

Dunn, MJ 2013, 'Uncertainty in ground support design and implementation in underground mining', in Y Potvin \& B Brady (eds), Proceedings of the Seventh International Symposium on Ground Support in Mining and Underground Construction, Australian Centre for Geomechanics, Perth, pp. 345-358

O'Toole, D \& Pope, S 2006, 'Design, testing and implementation of “in-cycle" shotcrete in the northern 3500 orebody', in DR Morgan \& HW Parker (eds), Proceedings of the 10th International Conference on Shotcrete for Underground Support, American Society of Civil Engineers, Reston.

Hilti 2011, Determination of the early strength of sprayed concrete with Hilti DX 450-SCT - Operating Instructions, Schaan.

ASTM International 2018, Standard Test Method for Obtaining and Testing Drilled Cores and Sawed Beams of Concrete (ASTM C42/C42M-18a), ASTM International, West Conshohocken. 